\title{
Exploitation of static and dynamic methods for the analysis of the mechanical nanoproperties of polymethylmetacrylate by indentation
}

\author{
Benaissa Soufiane, Habibi Samir, Semsoum Djameleddine, Merzouk Hassen, Mezough \\ Abdelnour \\ Mechanical Engineering Department, University of Mascara, 29000, LGIDD Laboratory of Relizane, 48000, Algeria. \\ soufiane.benaissa@univ-mascara.d₹, habibismr@univ-mascara.dz,djameleddine.semsoum@univ-mascara.d₹, \\ hassen.merzouk@univ-mascara.dz, abdelnour.mezough@univ-mascara.dz.
}

Boutabout Bénali

University of Djillali Liabes, Physical mechanics of materials Laboratory (LMPM), Sidi-Bel-Abbès, 22000, Algeria. bboutabout@yahoo.fr

Montagne Alex

National Higher School of Arts and Crafts (ENSAM), Mechanics, surfaces and materials processing Laboratory (MSMP) of Lille, France

alex.montagne@ensam.eu

\begin{abstract}
Elaborating an instrumented nanoindentation is to exercise nondestructive tests to be applied to volumes of polymethylmetacrylate (PMMA) materials in miniature. This work focuses on factors that explain the trends variation of mechanical properties like Young's modulus (E), contact hardness $(\mathrm{H})$ and indentation force $(\mathrm{P})$. The evolution of $\mathrm{E}$ and $\mathrm{H}$ with depth $(\mathrm{h})$ and $\mathrm{P}$ shows a $2.77 \mathrm{~nm}$ inflection point at low penetrations, separating two zones: the first increasing and the second decreasing. This is respectively explained by the surface hardening induced by preparing the material surface, and the existence of a surface hardness gradient denoted by an indentation size effect (ISE) observed at very low depths. Moreover, In addition, a critical penetration depth of $9.71 \mathrm{~nm}$ below which the surface effect dominates the variation of the penetrating load is detected. $\mathrm{E}$ and $\mathrm{H}$ results differences between dynamic and static modes are $8.46 \%$ and $6.44 \%$ inducing an overestimation of $35 \mathrm{MPa}$ in $\mathrm{E}$ value, and an underestimation of $1.23 \mathrm{MPa}$ in $\mathrm{H}$ value. This tends to affect the expected nanoscale precision of the indentation to determine the nanomechanical properties of PMMA.
\end{abstract}

KEYwORDs. Modulus; Hardness; Nanometer scale; Low indentation depths; Indentation size effect.

\section{OPEN ACCESS}

Citation: Benaissa, S., Habibi, S., Semsoum, D., Merzouk, H., Mezough, A., Boutabout, B., Montagne, A., Exploitation of static and dynamic methods for the analysis of the mechanical nanoproperties of polymethylmetacrylate by indentation, Frattura ed Integrità Strutturale, 56 (2021) 46-55.

Received: 14.01 .2021

Accepted: 18.01.2021

Published: 01.04.2021

Copyright: (C) 2021 This is an open access article under the terms of the CC-BY 4.0, which permits unrestricted use, distribution, and reproduction in any medium, provided the original author and source are credited. 


\section{INTRODUCTION}

$\mathrm{P}$ olymers offer interesting technological solutions in many activity fields. Due to the attractive mechanical properties of polymethylmetacrylate (PMMA) and its ability to be easily shaped, many researchers have focused on it to improve its resistance during the service [1-6]. Indeed, PMMA is widely used in nanotechnology, especially in mechanical and civil engineering, biomaterials, optical telecommunications, electronics, aeronautics, aerospace, etc. [7-13]. The nanoindentation technique has undergone a great technological evolution for more than a century, with the first tests carried out by Brinell [14] making it possible to define the notion of hardness, till today when such technique allows us to determine, at a nano-metric scale, the most commonly measured mechanical properties, such as Young's modulus and material hardness [15]. Regarding the nanometric scale, several parameters interact like the tip defect [16], instrument complacency [17], flow mode under indenter [18-20], micro-nano scaling-up [21], geometry of indenters, effect of indentation size, etc. All these might influence directly the accuracy of results. Many scientists have studied the variation of Young's modulus with shallow depth, resulting from a strain rate effect [22], the quality and geometry of the tip on PMMA [23] and the compliance of the frame depending on the applied force [24]. In nanoindentation, the size effect is often explained by the strain gradient plasticity (SGP) theory, based on dislocations that are geometrically necessary to accommodate the plastic deformation under the indenter $[25,26]$. The main objective of this study is to highlight by experiments the experimental tests of classical indentation at different levels of indentation forces, and the continuous stiffness measurement (C.S.M) via the integrated operating mode. We aim to assess the reliability of software out-puts for processing data, implemented in the instrumented indentation device (in static and dynamic modes), and estimate the measurement difference between both methods. We focus on studying the evolution of modulus and hardness with tip penetration depth and indentation force for very shallow depths, attempting to bring explanatory factors to the behavior of the material examined.

\section{SPECIMENS AND EXPERIMENTAL PROTOCOL}

7 he tests are carried out on an XP, MTS nanoindenter, equipped with a dynamic contact module (DCM) head of a very good resolution in force and displacement. The set is placed in an acoustic enclosure to avoid any environmental and acoustic disturbance. The tip used is a diamond Berkovich type indenter $(\mathrm{E}=1140 \mathrm{GPa}, \nu=$ $0.3)$, with a low tip defect $\mathrm{hp} \leq 20 \mathrm{~nm}$. The nanoindenter is installed on an anti-vibration springs table, to avoid any parasitic vibration. The imposed force is applied by a magnetic coil, and the displacement is estimated by capacitive measurement, with a surface approach speed of $9 \mathrm{nms}^{-1}$. The DCM head allows using the CSM method to obtain the dynamic properties of materials. The XP, MTS nanoindenter, which integrates the CSM module, allows a continuous measurement of the elasticity modulus and the hardness by successive oscillations of the tip during its movement. Without this option, the measurements could be only performed at the maximum penetration depth. The tests are carried out on a PMMA plane sample of very low roughness. The sample is fixed with a cyanoacrylate glue on the sample holder, screwed Aluminum and cleaned before tests with ethanol. PMMA is light, of a density being about half that of glass, resistant to atmospheric agents, easy to work with, and of its transparency greater than that of glass. In nanoindentation, the diameter and thickness of a sample are up to $30 \mathrm{~mm}$ and and $10 \mathrm{~mm}$, respectively. The types of tests and the operating conditions are shown in Tab. 1.

\begin{tabular}{lc}
\hline & \multicolumn{2}{c}{ Indentation device XP, TS } \\
Scale & Nano \\
Load range & $1-650 \mathrm{mN}$ \\
static mode & Constant time (30s loading / unloading); waiting time (15s); \\
dynamic mode & Strain rate $\left(0.05 \mathrm{~s}^{-1}\right)$; harmonic shift $(2 \mathrm{~nm})$; frequency $(45 \mathrm{~Hz}) ;$ \\
\hline
\end{tabular}

Table 1: Types of tests and operating conditions. 


\section{CHARACTERIZATION METHODOLOGY}

$\mathrm{I}$

$\mathrm{n}$ instrumented indentation, the hardness $(\mathrm{H})$ is defined as the ratio of maximum load $\mathrm{P}_{\max }$ to projected contact area $\mathrm{A}_{\mathrm{c}}$ :

$$
H=\frac{P_{\max }}{A_{c}}
$$

The reduced modulus of elasticity $E_{R}$ is linked to the slope (or stiffness $S$ ) of the curve on unloading by the relationship:

$$
E_{\mathrm{R}}=\frac{S}{2} \sqrt{\frac{\pi}{A_{c}}}
$$

where $\mathrm{E}_{\mathrm{R}}$ is related to the modulus of elasticity $\left(\mathrm{E}\right.$ and $\left.\mathrm{E}_{\mathrm{i}}\right)$ and to the Poisson coefficients $\left(\nu\right.$ and $\left.v_{\mathrm{i}}\right)$ of the material and the indenter, respectively:

$$
\frac{1}{E_{\mathrm{R}}}=\frac{1-v^{2}}{E}+\frac{1-v_{i}^{2}}{E_{i}}
$$

Eqns. (1) and (2) clearly show that the projected contact area $\left(A_{c}\right)$ is a key parameter in calculating the mechanical properties. Data analysis to obtain such properties is similar for the three scales, with a main difference being in the choice of the function used to estimate $A_{c}$. In nanoindentation, the most used area function (Eq. (4)) is that proposed by Oliver and Pharr [17], with $C_{n}$ coefficients denoting the least-squares adjustment parameters of the curve obtained from the CSM tests on fused silica,

$$
\mathrm{A}_{\mathrm{c}}=24.5 \mathrm{~h}^{2}{ }_{\mathrm{c}}+\mathrm{C}_{1} \mathrm{~h}^{1}{ }_{\mathrm{c}}+\mathrm{C}_{2} \mathrm{~h}^{1 / 2}{ }_{\mathrm{c}}+\mathrm{C}_{3} \mathrm{~h}^{1 / 4}{ }_{\mathrm{c}}+\ldots+\mathrm{C}_{8} \mathrm{~h}^{1 / 128}
$$

The used contact depth $\left(h_{c}\right)$ to calculate $A_{c}$ changes depending on the predominant strain mode in the material. The method of Oliver and Pharr [19] used when the material exhibits a sink-in (Eq. (5)), while the method of Loubet et al. [20] is exploited when the pile-up is predominant (Eq. (6)).

$$
\begin{aligned}
& A_{c-\text { sink in }}=24.56\left(h_{\max }-\frac{0.75 P_{\max }}{S}+h_{b}\right)^{2} \\
& A_{c-\text { pile } \operatorname{lp}}=24.56\left[1.2\left(h_{\max }-\frac{P_{\max }}{S}+h_{b}\right)\right]^{2}
\end{aligned}
$$

\section{RESULTS AND ANALYSIS}

$\mathrm{I}$

$\mathrm{n}$ nanoindentation the used area function [17] (Eq. (5)), of $\mathrm{C}_{\mathrm{n}}$ coefficients as the least squares adjustment parameters of the curve obtained from CSM tests on PMMA, is as follows:

$$
\mathrm{A}_{c}=24.4 h_{c}^{2}+974 h_{c}-2390 h_{c}^{1 / 2}-8950 \mathrm{~h} h_{c}^{1 / 4}-72.4 . h_{c}^{1 / 8}+438 h_{c}^{1 / 16}+731 h_{c}^{1 / 32}+888 h_{c}^{1 / 64}+969 h_{c}^{1 / 128}
$$

Evaluating the $\mathrm{h}_{\mathrm{f}} / \mathrm{h}_{\mathrm{m}}$ ratio to predict the deformation mode of the 48 characteristic points shown in Fig. 1 represent the ratios' values obtained at the nanoscale by analysing the curves. We find that for materials with a ratio greater than 0.83 , a pile-up was formed on the surface, while the sink-in appears when that was lower. The 0.83 value becomes therefore a 
limit value hence PMMA adopting an indenter strain in a sink-in form. So, the method of Oliver and Pharr [19] is used when the material presents a deflection of the faces of the hardness, as shown (Eq. 5).

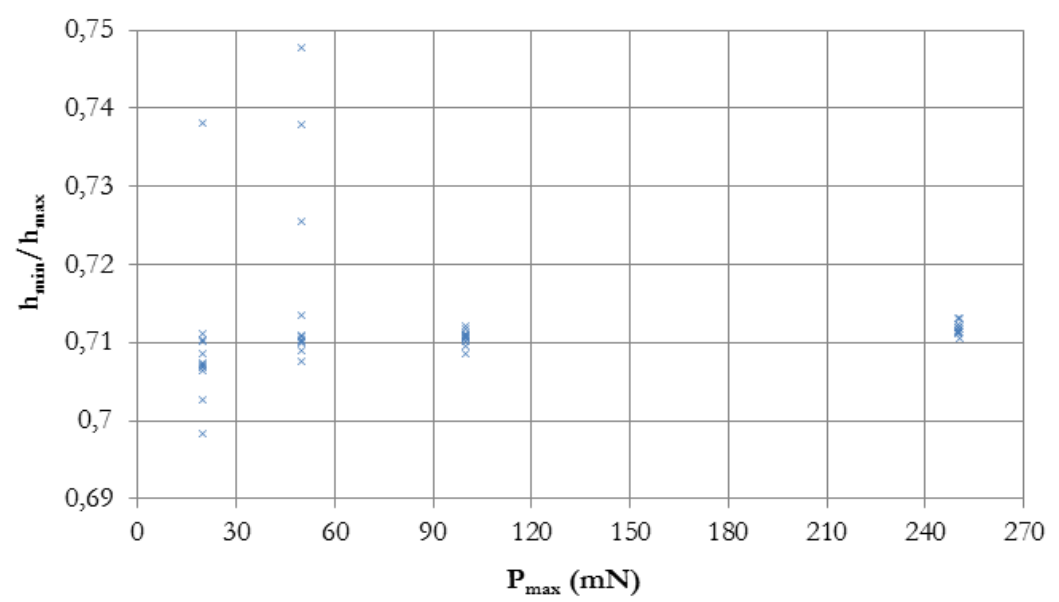

Figure 1: Evaluation of the ratio vs. the indentation force to predict the deformation mode.

Exploiting conventional nanoindentation was by interpolating results to collect mean hardnesses and modulus, respectively relating to the four ultimate loads ranges (see Figs. 2 and 3). For comparison, the evolution of these two properties, obtained by the CSM method, is also plotted (see Fig. 3 and 4).

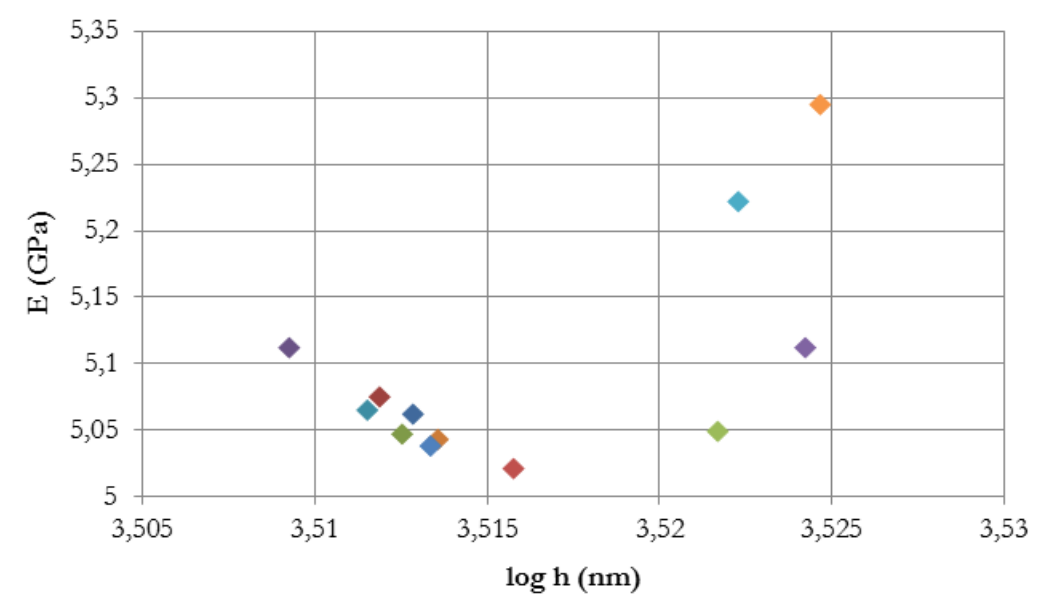

Figure 2: Modulus vs. displacement into surface in static mode.

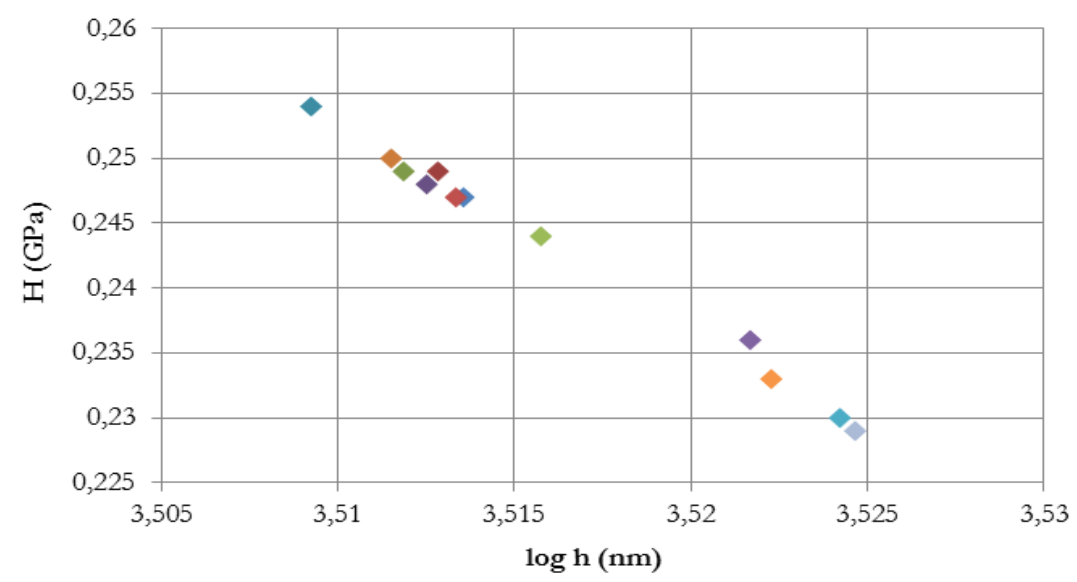

Figure 3: Hardness vs. displacement into surface in static mode. 
The two Figs. 2 and 3 illustrate the results of $\mathrm{E}$ and $\mathrm{H}$ obtained by the static method by interpolation. So that each characteristic point on these two graphical representations designates an ultimate indentation force test.

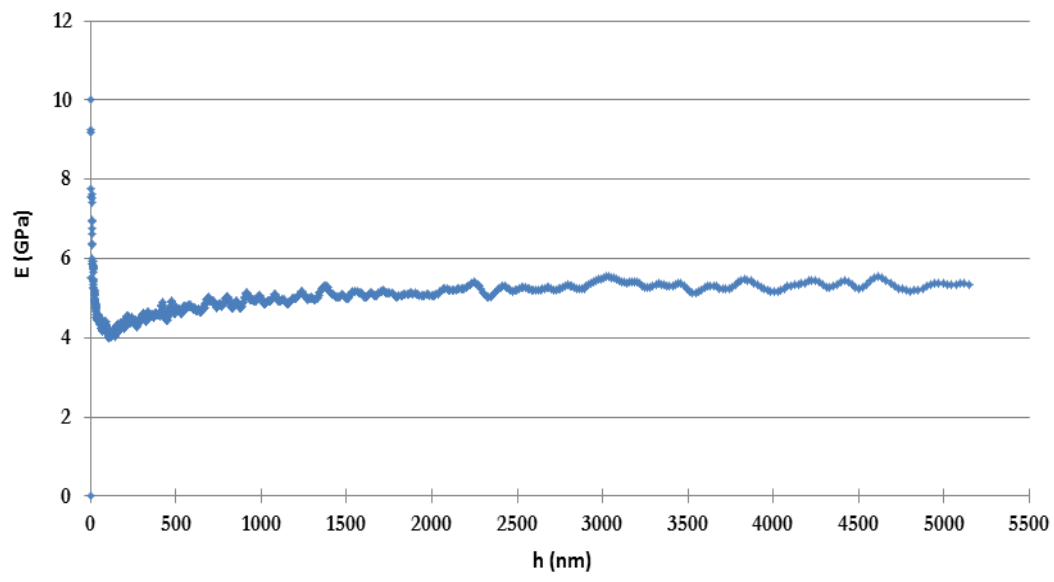

Figure 4: Modulus vs. displacement into surface in dynamic mode.

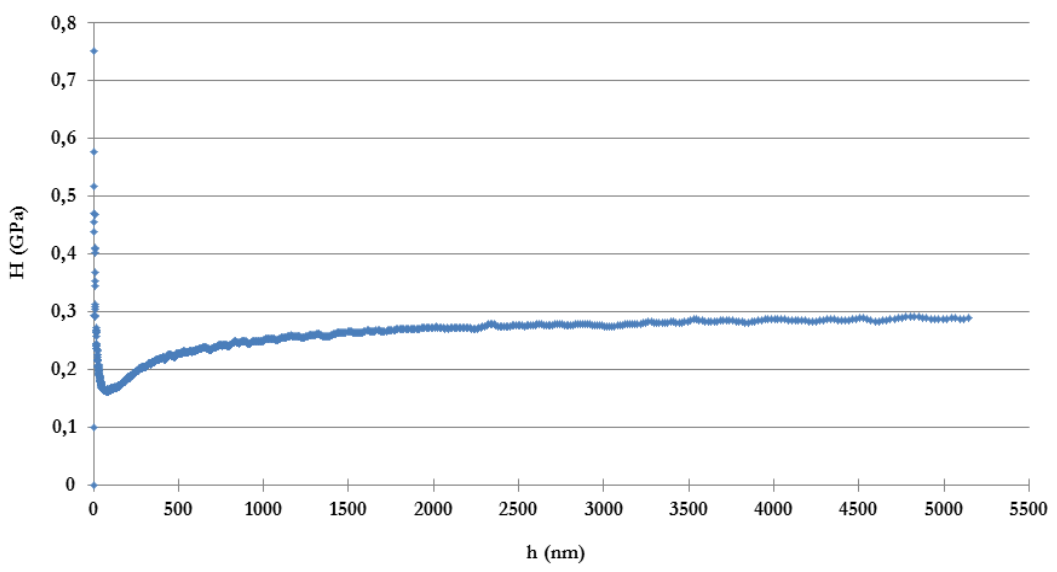

Figure 5: Hardness vs. displacement into surface in dynamic mode.

The graphical representations (see 4 and 5) illustrate the evolution of the continuous measurement of the properties E and $\mathrm{H}$ at each point. In contrary to the two previous ones (see Figs. 2 and 3).

\section{ESTIMATION OF NANOMECHANICAL PROPERTIES}

By using the static method

his is a point characterization at maximum progressive loads. The obtained parameters values are given in Tab. 2. $\mathcal{L}$

\begin{tabular}{ccc}
\hline$P_{\max }(\mathrm{mN})$ & $\mathrm{E}_{\text {moy }}(\mathrm{GPa})$ & $\mathrm{H}_{\text {moy }}(\mathrm{GPa})$ \\
50 & 5.095 & 0.243 \\
100 & 5.068 & 0.251 \\
250 & 5.056 & 0.247 \\
650 & 5.079 & 0.249 \\
\hline
\end{tabular}

Table 2: Mechanical properties in static mode. 
Following the four ranges of indentation loads for maximum penetrations between [2000-7300] nm, we obtain an average hardness of $0.247 \mathrm{GPa}$ and an estimated average Young's modulus of $5.08 \mathrm{GPa}$. From the results of the static method originates the fair value of the modulus of elasticity, according to the equation:

$$
\mathrm{E}_{\mathrm{IT}}=(5.08 \pm 0.02) \mathrm{GPa} \text { to the nearest } 0.3 \%
$$

And, the estimation of the indentation hardness, as well, as the following equation can show:

$$
\mathrm{H}_{\mathrm{TT}}=(0.247 \pm 0.003) \mathrm{GPa} \text { to the nearest } 1 \%
$$

\section{By using the dynamic method}

It is to continuously characterize parameters at loads corresponding to the contact depths at each characteristic point. For low indentation penetrations of the order of $(0.8 \div 11) \mathrm{nm}$ induced by low indentation forces which vary between $\left(9.83 .10^{-5} \div 1.54 .10^{-3}\right) \mathrm{mN}$ generate a Young's modulus which varies in the interval of $(6.3 \div 10)$ GPa. For low indentation depths between $(2.77 \div 11) \mathrm{nm}$ induced by low maximum loads which vary between $\left(4.27 .10^{-4} \div 1.47 .10^{-3}\right) \mathrm{mN}$ generate a contact hardness which varies in the interval from $(0.35 \div 0.74)$ GPa.

However, for values of displacement of the tip of the indenter between $(11 \div 5146) \mathrm{nm}$, a modulus of elasticity is recorded which varies in the range of $(4.5 \div 5.5) \mathrm{GPa}$ for values of loads between $\left(1.68 .10^{-3} \div 140\right) \mathrm{mN}$. And an indentation hardness that varies in the range of $(0.25 \div 0.30)$ GPa for forces between $\left(1.54 .10^{-3} \div 140\right) \mathrm{mN}$.

After integrating the CSM mode with the classical nanoindentation, we obtain an average hardness of $0.2662 \mathrm{GPa}$, and a Young's modulus estimated at $4.67 \mathrm{GPa}$ (See Eqns. 10,13), which leads to a fair value of the elasticity modulus, according to Eq. 10:

$$
\mathrm{E}_{\mathrm{IT}}=(4.67 \pm 0.02) \mathrm{GPa} \text { to the nearest } 0.4 \%
$$

And, the estimation of the indentation hardness, as well, as Eq. 11 shows:

$$
\mathrm{H}_{\mathrm{IT}}=(0.2662 \pm 0.0009) \mathrm{GPa} \text { to the nearest } 0.3 \%
$$

We have treated the obtained results with both methods, by using the statistic tool so-called "standard deviation" to estimate the precision of the central tendency with respect to the mean of the dispersion of the characteristic points.

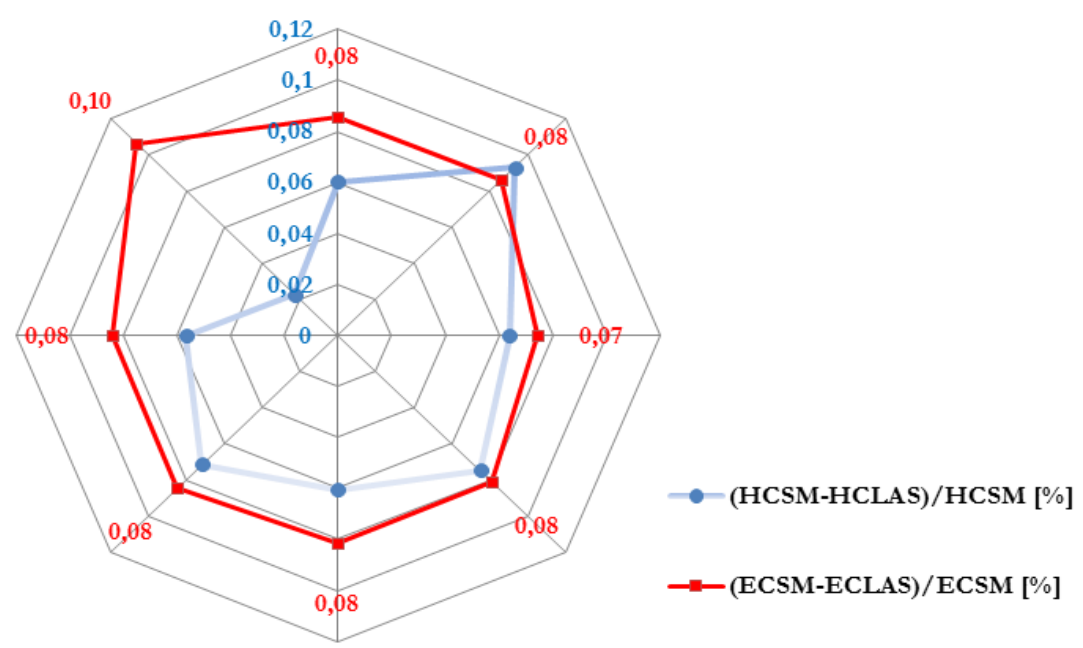

Figure 6: Radar graphical representation: Standard deviation of both methods, estimating (a) Young's modulus and (b) contact hardness.

By comparing the results consists the difference between both methods static (MS) and dynamic (MD) is determined, as shown in Eqn. 12 and 13, giving the hardness and modulus, respectively: 


$$
\begin{aligned}
& \Delta \mathrm{E} \% \text { (MS-MD) } \\
& =\frac{\left|E_{\text {sup }}-E_{\text {inf }}\right|}{E_{\text {sup }}} * 100 \\
& \Delta \mathrm{H}_{\text {(MS-MD) }}=\frac{\left|H_{\text {sup }}-H_{\text {inf }}\right|}{H_{\text {sup }}} * 100
\end{aligned}
$$

Hence, $\Delta \mathrm{E} \%$ (MS-MD) $=8,46 \%$ et $\Delta \mathrm{H} \%$ (MS-MD) $=6,44 \%$

\section{Evaluating mechanical nanoproperties at very low loadings and penetrations by using the CSM mode}

Exploitation of the results in dynamic mode to examine the behavior of PMMA, at low contact depths, between the specimen and the indenter's tip (see Figs .7 (a, b)).
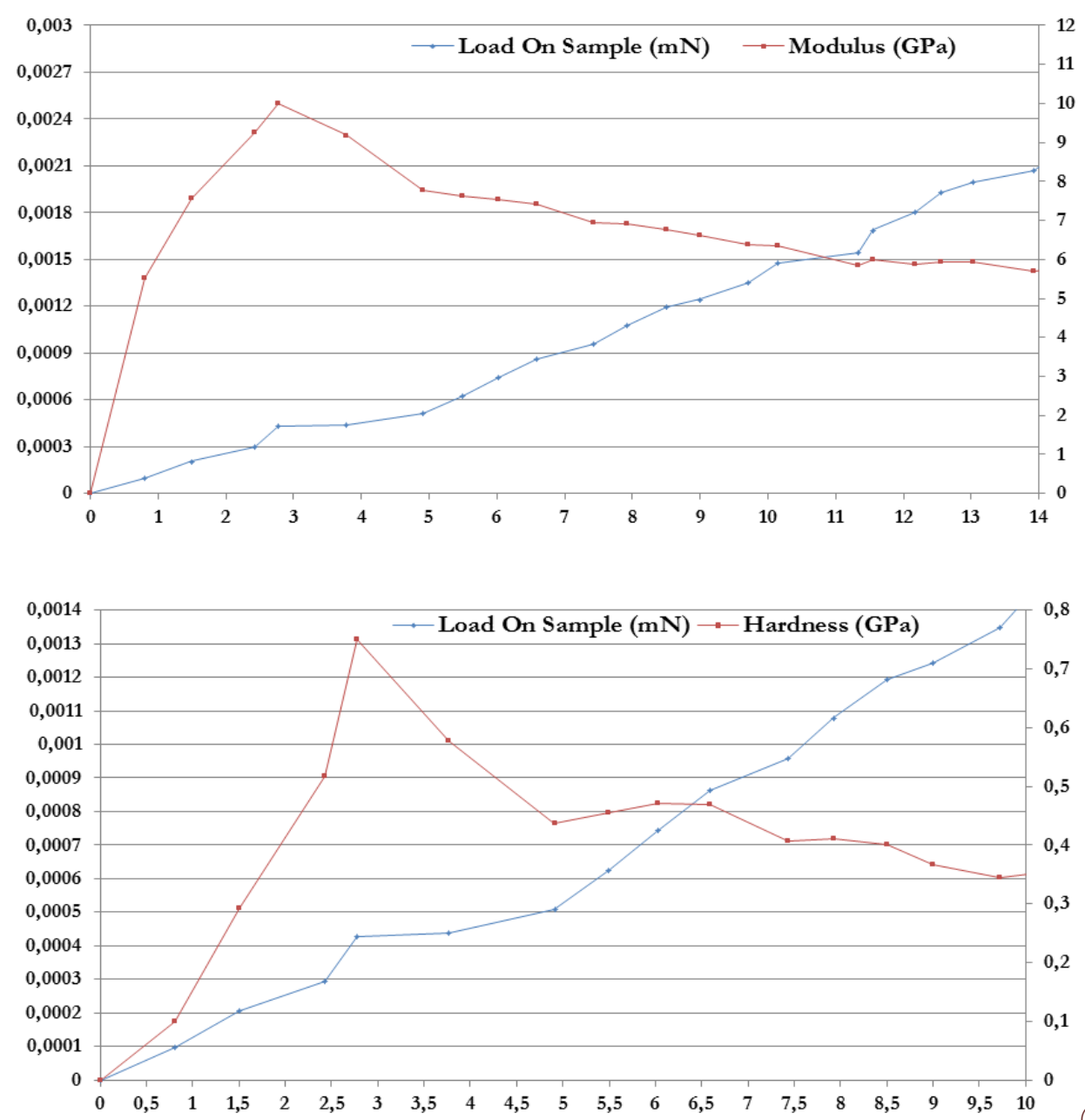

(a)

Figure 7: Evolution of (a) E and (b) H by CSM vs. the indentation force, at very low point penetrations.

The evolution of $\mathrm{E}$ shows a significant increase from $5.52 \mathrm{GPa}$ to the peak of $10 \mathrm{GPa}$ for $\mathrm{h}$ and $\mathrm{P}_{\max }$ respectively less $2.77 \mathrm{~nm}$ and $0.00044 \mathrm{mN}$ (see Fig. 7a). This increase in Young's modulus with depth, in the shallow depth range should results from a strain rate effect, as reported in the literature [22]. The Young's modulus increase in the shallow depth range results, from an overestimation of the contact area, reflecting the fact that the quality of the diamond tip, is not so bad because the Young's modulus remains almost constant above $20 \mathrm{~nm}$. It is worth noting that these results are in agreement with those obtained [23] on PMMA. Then, a decrease in $\mathrm{E}$ till $5.71 \mathrm{GPa}$ for $\mathrm{h}$ and $\mathrm{P}_{\max }$ respectively less than $13.92 \mathrm{~nm}$ and 
$0.0021 \mathrm{mN}$, was mentioned. Knowing that this modulus is an intrinsic property of materials, and assuming that the hypothesis is validated that Young's modulus is constant and independent of the applied load [17], this leads to the trend supposing that the device's compliance is dependent on the applied force, as some researchers have already reported [24]. Hence, this difference is probably related to experimental errors during the tests, and the deviation may be related to the relationships used for contact depth and contact area, as mentioned above. However, E converges towards an average constant value for $\mathrm{h}$ and respectively $\mathrm{P}_{\max }$ less than $5200 \mathrm{~nm}$ and $146 \mathrm{mN}$.

The evolution in $\mathrm{H}$ has recorded a significant increase of 0.1 to $0.75 \mathrm{GPa}$ for $\mathrm{h}$ and $\mathrm{P}_{\max }$ respectively less than $2.77 \mathrm{~nm}$ and $0.00042 \mathrm{mN}$ (see Fig. 7b), which can be explained by a superficial hardening induced by the preparation of the material surface (brutal mechanical polishing). A sharp decrease is noted in H down to 0.34 GPa for (h, Pmax) less than (9.71 nm, $0.0013 \mathrm{mN}$ ). Such observations can be attributed on the one hand to the role of the surface effect on nanohardness for very low penetration depths, and on the other hand to the existence of a critical penetration depth below which the surface effect dominates the variation of the penetrating load in the vicinity of $9.71 \mathrm{~nm}$. That is the ISE generally leading to a decrease in hardness as the indentation load increases. These results confirm the works of Zhang and Xu [27]. On the other hand, observations can be attributed to the effect of the contact size which is comparable to the grain size of the material [28]. However, the obtained results show that $\mathrm{H}$ remains constant when the indentation depth and $\mathrm{P}_{\max }$ are respectively less than $5200 \mathrm{~nm}$ and $146 \mathrm{mN}$. In nanoindentation, the size effect is often explained by the theory of Strain Gradient Plasticity (SGP), based on dislocations that are geometrically necessary to accommodate the plastic deformation under the indenter $[25,27]$.

Now, by comparing the results of dynamic and static modes with those of the literature, we should notice that the estimation of the uncertainties in evaluating the Young's modulus and hardness are respectively in orders of $8.46 \%$ and $6.44 \%$. Therefore, there is a tendency to overlook deviations originating from the evaluations of the measured mechanical properties, and in particular an overestimation of $35 \mathrm{MPa}$ in the value of the modulus of elasticity and an underestimation of $1.23 \mathrm{MPa}$ in that of the contact hardness. This has likely to affect the expected precision in indentation at nanoscale while determining the nanomechanical properties of the studied polymer. For the Berkovich tip, an overestimation of about 5.23\% for PMMA (4670 vs $4426 \mathrm{MPa}$ [22]) has been recorded. According to Briscoe and Sebastian [23], the results have to be interpreted as an effect of the high hydrostatic pressure, existing under the Berkovich indenter for PMMA.

\section{CONCLUSION}

- The difference in the results of $\mathrm{E}$ and $\mathrm{H}$ between the dynamic and static modes are respectively: $8.46 \%$ and $6.44 \%$ inducing an overestimation of $35 \mathrm{MPa}$ in value of $\mathrm{E}$ and an underestimation of $1.23 \mathrm{MPa}$ in value de $\mathrm{H}$. They tend to affect the expected nanometric precision of the indentation to determine the nanomechanical properties of PMMA.

- The indentation mode provided with CSM offers several advantages for the mechanical characterization of polymers in particular the external referencing, the optimization of the effort and the time, as well as the high precision for very low loadings compared to the classic technique which does not allow obtaining such efficient results.

- The evolution of Young's modulus and contact hardness shows the existence of a surface hardness gradient called the indentation size effect (ISE) observed at very weak penetrations in the vicinity of $2.77 \mathrm{~nm}$.

- The identification of an estimated critical penetration depth of $9.71 \mathrm{~nm}$ below which the surface effect on nanohardness dominates the variation in the penetration charge.

- In perspective, a comparative study of the different families of materials by the use of the CSM mode to explore the effect of indentation size is envisaged to examine indentor plasticity at very low nanometric indentation depths.

\section{ACKNOWLEDGMENTS}

7 his research was supported by the General Directorate of Scientific Research and Technological Development (DGRSDT: Direction Générale de la Recherche Scientifique et du Développement Technologique) of Algeria. The authors gratefully acknowledge the scientific support of the two research teams from the Lille Mechanics Unit 
(France) and the Laboratory of Industrial Engineering and Sustainable Development (LGIDD), University of Relizane (Algeria).

\section{REFERENCES}

[1] Kaddouri, A., Serier, B., Kaddouri, K., Belhouari, M. (2020). Experimental Analysis of the Physical Degradation of Polymers - The Case of Polymethyl Methacrylate, Frattura ed Integrità Strutturale, 53, pp. 66-80.

DOI: 10.3221/IGF-ESIS.53.06.

[2] Drai, A., Aour, B., Belayachi, N., Talha, A., Benseddiq, N. (2020). Finite element modeling of the behavior of polymethyl-methacrylate (PMMA) during high pressure torsion process, Frattura ed Integrità Strutturale, 52, pp. 181196. DOI: 10.3221/IGF-ESIS.52.15.

[3] Ayatollahi, M.R., RashidiMoghaddama, M., Razavi, S.M.J., Berto, F. (2006). Geometry effects on fracture trajectory of PMMA samples under pure mode-I loading, Engineering Fracture Mechanics, 163, pp. 449-461.

DOI: 10.1016/j.engfracmech.2016.05.014.

[4] Torabi, A.R., Campagnolo, A., Berto, F. (2015). Local strain energy density to predict mode II brittle fracture in Brazilian disk specimens weakened by V-notches with end holes, Materials and Design, 69 (15), pp. 22-29. DOI: 10.1016/j.matdes.2014.12.037.

[5] Berto, F., Cendon, D.A., Lazzarin, P., Elices.M. (2013). Fracture behaviour of notched round bars made of PMMA subjected to torsion at $-60^{\circ} \mathrm{C}$, Engineering Fracture Mechanics, 102, pp. 271-287.

DOI: 10.1016/j.engfracmech.2013.02.011.

[6] Cendón, D.A., Berto, F., Lazzarin, P., ElicesCalafat. M. (2013). The Cohesive Crack Model Applied to Notched PMMA Specimens Obeying a Non Linear Behaviour under Torsion Loading, Key Engineering Materials, 577-578, pp. 49-52. DOI: 10.4028/www.scientific.net/KEM.577-578.49.

[7] Wenhua, Y., Zeyu, X., Yuming, Y., Jun, Y., Xiaodan, L., Huiqin, W., Shuang, W., Yufang, X., Yunong, Y. (2019). Aging behavior and lifetime prediction of PMMA under tensile stress and liquid scintillator conditions, Journal: Advanced Industrial and Engineering Polymer Research. DOI: 10.1016/j.aiepr.2019.04.002.

[8] Bussi, Y., Golan, S., Dosoretz, CG., Eisen, MS. (2018). Synthesis, characterization and performance of polystyrene/PMMA blend membranes for potential water treatment, Journal of Desalination. 431, pp.35-46. DOI: 10.1016/j.desal.2017.12.024.

[9] Münker, T.J.A.G., Van de Vijfeijken, S.E.C.M., Mulder, C.S., Vespasiano, V., Becking, A.G., Kleverlaan, C.J., and al. (2018). Effects of sterilization on the mechanical properties of poly(methyl methacrylate) based personalized medical devices, Journal of the Mecchanical Behavior of Biomedical Materials. 81, pp.168-172.

DOI: 10.1016/j.jmbbm.2018.01.033.

[10] Kowalonek, J., Kaczmarek, H., Kurzawa, M. (2016). Effect of UV-irradiation on fluorescence of poly (methyl methacrylate) films with photosensitive organic compounds, Journal of Photochemistry and Photobiology A: Chemistry. 319-320, pp. 18-24. DOI: 10.1016/j.jphotochem.2015.12.017.

[11] Manjunatha, H.C. (2017). A study of gamma attenuation parameters in poly methylmethacrylate and Kapton, Journal of Radiation Physics and Chemistry. 137, pp. 254-259. DOI: 10.1016/j.radphyschem.2016.01.024.

[12] Zhong, Z.W., Wang, Z.F., Zirajutheen, B.M.P. (2005). Chemical mechanical polishing of polycarbonate and polymethylmethacrylate substrates, Journal of Microelectronic Engineering. 81, pp. 117-124. DOI: 10.1016/j.mee.2005.04.005.

[13] Ali, U., Karim, K.J.B.A., Buang, N.A. (2015). A review of the properties and applications of poly (methylmethacrylate) (PMMA), Journal of Polymer Reviews. 55, pp. 678-705. DOI: 10.1080/15583724.2015.1031377.

[14] Tabor, D. (1951). The hardness of metals, Monographs on the physics and chemistry of materials, Oxford Clarendon Press; Londres: Oxford University Press.

[15] Fischer-Cripps, A.C. (2002). Facteurs affectant les données de test de nanoindentation, Nanoindentation, SpringerVerlag New York Inc, pp. 77-104. DOI: 10.1007/978-1-4419-9872-9.

[16] Hochstetter, G., Jimenez, A., Loubet, J.L. (1999). Strain-rate effects on hardness of glassy polymers in the nanoscale range. Comparison between quasi-static and continuous stiffness measurements, J. Macromol. Sci. Part B-Phys. B 38 (5-6), pp. 681-692. DOI: 10.1080/00222349908248131.

[17] Oliver, WC., Pharr, GM. (1992). An improved technique for determining hardness and elastic-modulus using load and displacement sensing indentation experiments, Journal of Materials Research, 7(6), pp. 1564-1583.

DOI: https://doi.org/10.1557/JMR.1992.1564. 
[18] Alcala, J., Barone, A.C., Anglada, M. (2000). L'influence du durcissement plastique sur les modes de déformation de surface autour des vickers et des empreintes sphériques, Acta Mater, 48, pp. 3451-3464.

DOI: 10.1016 / S1359-6454 (00) 00140-3.

[19] Oliver, W.C., Pharr, G.M. (2004). Mesure de la dureté et du module élastique par indentation instrumentée: progrès de la compréhension et amélioration de la méthodologie, J. Mater. Res. 19 (1), pp. 3-20.

DOI: $10.1557 / j \mathrm{mr} .2004 .19 .1 .3$.

[20] Loubet, J.L., Bauer, M., Tonck, A., Bec, S., Gauthier-Manuel, B. (1993). Nanoindentation with a surface force apparatus, NATO Advanced study institute Series E. M. Natasi, 233, pp. 429447. DOI: 10.1007/978-94-011-1765-4_28.

[21] Hang, W., Zhou, L., Shimizu, J., Yuan, J. (2013). A robust procedure of data analysis for micro/nano indentation. Precision Engineering, 37, pp. 408-413. DOI: 10.1016/j.precisioneng.2012.11.003.

[22] Hochstetter, G., Jimenez, A., Cano, J.P., Felder, E. (2003). An attempt to determine the true stress-strain curves of amorphous polymers by nanoindentation, Tribology International, 36, pp. 973-985.

DOI: $10.1016 / \mathrm{S} 0301-679 \mathrm{X}(03) 00107-5$.

[23] Briscoe, B.J., Sebastian, K.S. (1996). The elastoplastic response of poly(methylmethacrylate) to indentation, Proc. R. Soc. Lond, A 452, pp. 439-57. DOI: 10.1098/rspa.1996.0023.

[24] Cabibbo, M., Ricci, P., Cecchini, R., Rymuza, Z., Sullivan, J., Dub, S., Cohen, S. (2012). Un protocole international d'étalonnage circulaire pour les mesures de nanoindentation, Micron, 43, pp. 215-222. DOI: $10.1016 /$ j.micron.2011.07.01.

[25] Nix, W.D., Gao, H. (1997). Effets de taille d'indentation dans les matériaux cristallins: une loi pour la plasticité du gradient de déformation, J. Mech. Phys. Solids, 46 (3), pp. 411-425. DOI: 10.1016/S0022-5096(97)00086-0.

[26] Elmustafa, A.A., Stone, D.S. (2003). Nanoindentation and the Indentation Size Effect: Kinetics of Deformation and Strain Gradient Plasticity. J. Mech. Phys. Solids, 51 (2), pp. 357-381. DOI: 10.1016/S0022-5096(02)00033-9.

[27] Zhang, T.Y., Xu, W.H., Zhao, M.H. (2004). The role of plastic deformation of rough surfaces in the size-dependent hardness, Acta Materialia 52, pp. 57-68. DOI: 10.1016/j.actamat.2003.08.026.

[28] Tsui, T.Y., Pharr, G.M. (1999). Substrate effects on nanoindentation mechanical property measurement of soft films on hard substrates, J. Mater. Res. 14 (1), pp.292-301. DOI: 10.1557/JMR.1999.0042. 